

\section{Panta Rei \\ Revista Digital de Ciencia \\ y Didáctica de la Historia}

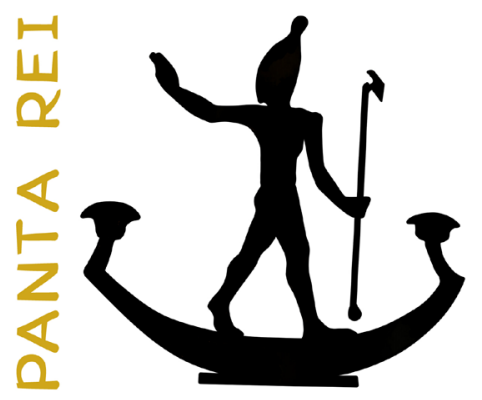

2017

Revista anual

Fecha de inicio: 1995

Revista Panta Rei. pantarei@um.es

Edita:

Centro de Estudios del Próximo Oriente y la

Antigüedad Tardía - CEPOAT

Edificio Universitario Saavedra Fajardo.

Universidad de Murcia

C/ Actor Isidoro Máiquez, 9

30007 - MURCIA - ESPAÑA

Teléfono: (+34) 868883890

cepoat@um.es

Web: www.um.es/cepoat/pantarei

Edición 2017

ISSNe: 2386-8864

ISSN: 1136-2464

Depósito legal: MU-966-1995
cepoAt

UNIVERSIDAD DE MURCIA centro de estudios del próximo oriente y la antigüedad tardia

En Portada: Kaaba durante el Ramadán. Fotografía de Abdullah Shakoor. Creative Commons CCO.

Responsables de los textos: Sus autores.

Responsable de la presente edición: Consejo Editorial Panta Rei. 


\section{CONSEJO DE REDACCIÓN}

\section{Coordinador editorial}

Egea Vivancos, Alejandro

[Didáctica de las Ciencias Sociales, UMU]

\section{Editores}

Botí Hernández, Juan Jesús

[CEPOAT, UMU]

Meseguer Gil, Antonio José

[UNED]

Sáez Giménez, David Omar

[CEPOAT, UMU]

Sánchez Mondéjar, Celso Miguel

[Patrimonio Inteligente]

\section{Secretaria}

Arias Ferrer, Laura

[Didáctica de las Ciencias Sociales, UMU]

\section{Responsable informático}

Martínez García, José Javier

[CEPOAT, UMU]

\section{Traducción y corrección lingüística}

Martínez Martínez, Cristina

[Sociedad Española de Lenguas Modernas]

Albaladejo Albaladejo, Sara

[ISEN, UMU]

\section{CONSEJO ASESOR}

Albero Muñoz, M. ${ }^{a}$ del Mar

[H. ${ }^{a}$ del Arte, UMU]

Chapman, Arthur

[History Education, UCL, Reino Unido]

Cobacho López, Ángel

[Derecho, UMU]

Egea Bruno, Pedro M. ${ }^{a}$

[Historia Contemporánea, UMU]

García Atienzar, Gabriel

[Prehistoria, UA]

González Monfort, Neus

[Didáctica de las Ciencias Sociales, UAB]

Haber Uriarte, María

[Prehistoria, UMU]

Hutson, Scott R.

[Anthropology, UK, EEUU]

Irigoyen López, Antonio

[Historia Moderna, UMU]

Mahony, Simon

[Digital Humanities, UCL, Reino Unido]

Marsilla de Pascual, Francisco Reyes

[Técnicas historiográficas, UMU]

Miralles Maldonado, José Carlos

[Filología Clásica, UMU]

Molina Gómez, José Antonio

[Historia Antigua, UMU]

Noguera Celdrán, José Miguel

[Arqueología, UMU]

Pérez Molina, Miguel Emilio

[Filología Clásica, UMU]

Prados Martínez, Fernando

[Arqueología, UA]

Sánchez Ibáñez, Raquel

[Didáctica de las Ciencias Sociales, UMU]

Sancho Gómez, Miguel Pablo

[Educación, UCAM]

Vilar García, María José

[Historia Contemporánea, UMU]

Zamora López, José Ángel

[Próximo Oriente Antiguo, CCHS-CSIC] 

Artículos

Entre el mito y la historia: el Éxodo de los israelitas desde Egipto a Canaán.

David Villar Vegas.

El Cerro de la Ermita de La Encarnación (Caravaca de la Cruz, Murcia): santuario y territorio en el mundo ibérico del Sureste peninsular.

Leticia López-Mondéjar.

Estelas discoideas y mundo funerario en la Asturias antigua.

Narciso Santos Yanguas......

Filosofía y paganismo en las postrimerías del Imperio Romano de Occidente. El caso del cónsul Mesio Febo Severo.

Rafael González Fernández y Miguel Pablo Sancho Gómez.

Dinámicas identitarias en el Mundo Actual: la religión como identidad frente al otro.

Rafael Ruiz Andrés y Francisco Javier Fernández Vallina.

El patrimonio fenicio-púnico. Claves para su socialización, puesta en valor y uso didáctico.

Helena Jiménez Vialás.

¿Cómo se enseña la llustración en $22^{\circ}$ de Bachillerato? Un análisis de los libros de texto, sus contenidos y la cuestión de género.

Helena Rausell Guillot..... 109

The Role of Local History in Elementary and Secondary Schools in Slovenia: An Evaluation of the Centre for School and Outdoor Education.

Danijela Trškan

Reseñas

Richardson, S. y Garfinkle, S. (eds.) (2016). Scholarship and Inquiry in the Ancient Near East (=Journal of Ancient Near Eastern History special issue, vol. 2/2, 2015) Berlin: de Gruyter. 179 págs.

Juan Álvarez García.

Guldi, J. y Armitage, D. (2016). Manifiesto por la Historia (traducción de Galmarini, M. A. The History Manifesto, 2014). Madrid: Editorial Alianza. 292 págs.

Juan Jesús Botí Hernández y David Omar Sáez Giménez.....

Normas de publicación/Publishing rules 



\title{
Filosofía y paganismo en las postrimerías del Imperio Romano de Occidente. El caso del cónsul Mesio Febo Severo
}

\author{
Philosophy and paganism at the end of the Western Roman Empire. The case of the \\ consul Messius Phoebus Severus
}

Rafael González Fernández ${ }^{1}$

Universidad de Murcia

Miguel Pablo Sancho Gómez²

Universidad Católica San Antonio (Murcia)

Recibido: 30/01/2017

Aceptado: 05/07/2017

Para citar este artículo: González Fernández, R., y Sancho Gómez, M. P. (2017). Filosofía y paganismo en las postrimerías del Imperio romano de Occidente. El caso del cónsul Mesio Febo Severo. Panta Rei. Revista Digital de Ciencia y Didáctica de la Historia, 59-69.

ISSNe: 2386-8864

DOI: $10.6018 /$ pantarei/2017/4

\section{Resumen}

Con la aceptación del cristianismo como religión oficial del Imperio, el proceso de hostilidad hacia los otros cultos, ya originado casi un siglo antes al final del reinado de Constantino, se verá reforzado y ampliado con la promulgación de numerosos decretos que muy pronto comenzaron a poner en apuros tanto a los practicantes del paganismo como a los considerados heréticos. Pese a que las acciones gubernamentales junto a las medidas de la propia Iglesia propiciaron el cierre de un creciente número de templos y la clausura de numerosos cultos e instituciones educativas, ciertas prácticas y pervivencias del mundo clásico perduraron a través del tiempo y siguieron manifestándose en periodos sorprendentemente tardíos. Ofreceremos aquí un caso en concreto, el del colaborador del emperador Procopio Antemio, Mesio Febo Severo, cónsul en el año 470 pese a su abierta condición de filósofo y pagano.

\section{Palabras clave}

Historia de Europa, Filosofía, Conflicto religioso, Trasfondo cultural, Fuentes clásicas.

\section{Abstract}

With the acceptance of Christianity as official religion of the Empire, the process of hostility towards the other cults, originated almost a century before at the end of the reign of Constantine, will be strengthened and expanded by the enactment of numerous decrees which soon began to trouble both the practitioners of paganism and those considered heretical among Christians. Although

1 Para contactar con este autor: Rafael González Fernández. Universidad de Murcia. rafaelg@um.es. 2 Para contactar con este autor: Miguel Pablo Sancho Gómez. Universidad Católica San Antonio (Murcia). mpsancho@ucam.edu. 
government actions along with the measures of the very Church led to the closure of a growing number of temples and of numerous cults and educational institutions, certain practices and survivals of the Classical world persisted over time and continued to manifest in surprisingly late periods. We will offer here a specific case, that of the collaborator of the emperor Procopius Anthemius, Messius Phoebus Severus, consul in the year 470 despite of his open condition of philosopher and pagan.

\section{Keywords}

European History, Philosophy, Religious Conflict, Cultural Background, Classical Literature.

\section{Introducción}

Con la proclamación de Teodosio como Augusto en 379 comenzó el reinado que vería la confirmacin definitiva de la supremacía del cristianismo en todos los ámbitos de la vida pública, quedando refrendado esta vez por los decretos y la legislación imperial (Bravo, 2010; Ernesti, 1998; Leppin, 2009; Williams y Friell, 1994).

Pese a que durante algunos años se produjo un amigable acercamiento a las aristocracias paganas de Roma, la omnipresente influencia de Ambrosio, obispo de Milán, logró al final una gran victoria sobre los otros cultos religiosos, que se plasmó en edictos que garantizaban los privilegios del culto cristiano, hasta el punto de declararlo exclusivo y único, quedando desde entonces el resto de creencias fuera de la ley (Trombley, 1993, 3; según este autor la verdadera represión contra los sacrificios y sus practicantes comenzó con la ley del 21 de diciembre de 381 dada por el emperador Teodosio (Cod.Theod. XVI 10, 7; González-Blanco, 1998).

El Edicto de Tesalónica (380) desamparaba a las corrientes que dentro del culto se alejaban de Nicea, y declaraba herejes a los arrianos, protegidos hasta entonces por el anterior emperador Valente, que de hecho les había entregado el control de la mayoría de iglesias de Constantinopla. Se puede considerar que desde el punto de vista de la política religiosa fue la obra culminante del emperador Teodosio I El Grande (Cameron, 2010; Lee, 2013; Salzman, Sághy y Testa, 2015; Testa y Santini, 2014; Watts, 2015). Entre 389 y 392 se promulgaron nuevas leyes que propiciaron el acoso y derribo del paganismo, literalmente hablando, pues, aunque en ocasiones decretos concretos ordenaban la salvaguarda de un templo en específico, la religión tradicional dejó de estar permitida ${ }^{3}$.

Pese a que el paganismo, especialmente en sus formas residuales y marginales, perduró aún largo tiempo tras Teodosio, tal y como ha sido demostrado en ciertos trabajos (McKenna, 1938; MacMullen, 1981, 1984 y 1997), el aparato de gobierno del Imperio Romano, ya definitivamente cristiano, se vio "purgado" mediante sucesivas disposiciones legales en las que se prohibía ejercer cargos públicos a los considerados desde entonces herejes o idólatras (Fernández, 1983; Montero 1990; Watts, 2004). El proceso, ya muy visible en el periodo teodosiano, quedó refrendado durante el siglo V en ambas mitades del Imperio (Brown, 1997; Busine, 2015; Rapp, 2013; Salzman, 2002; Shanzer, 2016). Casos como el de los años 390-392, en los que ambos Prefectos del Pretorio fueron aristócratas paganos fuertemente comprometidos con los cultos tradicionales (Eutolmio Taciano y Nicómaco Flaviano), pasaron muy pronto a convertirse en rarezas, y aún en fenómenos

3 Empezando con la ley contra la magia del 16 de agosto de 389 (Cod. Theod. IX 16, 11); después la famosa ley del 24 de febrero de 391 prohibía expresamente la adoración de ídolos, los sacrificios y el culto en los templos (Cod. Theod. XVI 10, 10). Se contemplaban multas y penas monetarias: los miembros del aparato de gobierno y la burocracia pagarán en función de su status (los funcionarios superiores sufrirán multas más pequeñas, y los secretarios y servidores de rango bajo, más elevadas); esta ley parece indicar que los paganos en la burocracia imperial eran numerosos. La ley del 8 de noviembre del 392 prohibía las ofrendas de incienso y los sacrificios a imágenes, así como el uso de cualesquiera artes adivinatorias. Se amenaza también con multas a los jueces que no la hagan cumplir (Cod. Theod. XVI 10, 12). Ya en 385, Teodosio I exhortó a Cinegio, su Prefecto del Pretorio de Oriente, a hacer cumplir la prohibición de los sacrificios con propósitos divinatorios (Cod. Theod. XVI 10, 9). 
inauditos. Desde ese momento los funcionarios y servidores que en su fuero íntimo mantuviesen otras creencias, se verían abocados al secretismo más absoluto. El caso del abogado del fisco e historiador Zósimo es uno de los más célebres, pero se podrían ofrecer otros, como el del controvertido Prefecto del Pretorio de Oriente entre 532 y 541, Juan de Capadocia (Procop., Pers I 25, 4-10), o el obispo Pegaso, que según Juliano mantenía en perfecto estado los cultos de Aquiles, Atenea y Héctor en Ilion (Ep. 79; se remonta a sucesos del año 354). El fenómeno también puede rastrearse en la legislación imperial, donde aparecen crecientes penas y amenazas para casos muy relacionados ${ }^{4}$. A la prohibición de ejercer cargos públicos se añadió después la de pertenecer al ejército, heredar, testamentar o desempeñar la enseñanza (Blumenthal, 1978; Cod. lust. I 5 18, 4 y I 11 10, 2). En Cod. lust. I 11, 9 se prohíbe expresamente cualquier tipo de herencia, donación o legado relacionados con lugares de culto pagano.

Quizás dentro de la mencionada tendencia "criptopagana" podría encuadrarse también la figura de Procopio Antemio (467-472). Protegido por el emperador de Oriente León I (457-474), con el que mantenía excelentes relaciones y que le había elevado a la distinción patricia, fue enviado a Italia con un ejército y el rango de César; se hizo así con el poder en Occidente tras el vacío de dieciséis meses acontecido después del fallecimiento de Libio Severo en agosto de 465. El generalísimo Ricimero, como no podía ser de otro modo, había dado su consentimiento para recibir en el Oeste al nuevo emperador, pese a los recelos que causaban entre algunos su pertenencia a la nobleza de Constantinopla y su cultura griega (Heather, 2006; MacGeorge, 2002). Antemio fue además proclamado Augusto por sus tropas, cuando ya se encontraba en los alrededores de Roma.

\section{La filosofía antes del fin del Imperio en Occidente}

Desde el mismo comienzo del denominado Neoplatonismo, la exégesis, con su correspondiente adaptación, adecuación y reordenación de los viejos mitos, unida a una organización piramidal de los cultos y a una nueva estructura religiosa desde el punto de vista teológico, habían sido las líneas maestras tanto de la filosofía como de las religiones antiguas (O’Meara, 2006; Ramos, 2006). Pese a que en ocasiones se ha acusado a los filósofos neoplatónicos de rechazar los asuntos mundanos y la política, lo cierto es que las virtudes cardinales ya definidas por Platón sufrieron una reelaboración en el intento consciente de hacer al ser humano cada vez más parecido a los dioses. Las virtudes cívicas pasaron a ser la base esencial. Así, la sabiduría, el coraje, la moderación y la justicia se convirtieron en elementos primordiales del proceso de divinización, que dejó de asociarse exclusivamente al rechazo del mundo, aunque la corriente ascética del paganismo filosófico nunca desapareció por completo (Francis, 1995).

La Teúrgia propició que las escuelas filosóficas se fuesen imbuyendo cada vez más de un devoto sentido religioso rayano en la superstición; tal milagrería efectuada por las estatuas de los dioses, los portentos y epifanías, y la proliferación de hombres santos también de religión pagana (Brown, 1971; Fowden, 1982) entran en el nuevo espectro cultural de los tiempos y en las necesidades espirituales y mentales de las poblaciones imperiales en general, y de los fieles en

\footnotetext{
4 Existían prohibiciones y severos castigos para los conversos al paganismo, prueba de que el fenómeno existió: Cod. Theod. XVI 7, 1 (2 de mayo del año 381): cristianos convertidos al paganismo perderán su derecho de testamentar, y cualquier herencia redactada en esas circunstancias quedará invalidada. Cod. Theod. XVI 7, 2 (20 de mayo de 383): Una aclaración de la anterior ley: cristianos probados que regresen al paganismo no podrán testamentar ni dictar su última voluntad. Cod. Theod. XVI 7, 3 (21 de mayo de 383): una aclaración de la ley inmediatamente anterior. Los cristianos que se conviertan al paganismo, judaísmo, u otra religión, pierden el derecho de hacer un testamento. Los maniqueos y otras sectas similares serán castigados si se descubren sus reuniones y rituales, con la obligación de legar sus bienes a otros familiares o al estado. Cod. Theod. XVI 7, 5 (11 de mayo o 9 de junio del año 391): Personas de rango o clase heredados familiarmente que abandonen el cristianismo serán castigados con la pérdida de dichos honores y posición, además de estigmatizados con infamia.
} 
particular, a partir del siglo III (Alföldi, 1979; Brown, 1989; Gigon, 1970; Lee, 2000; Lieu y Montserrat, 1996; Momigliano 1970; Sánchez, 1986). La especulación filosófica y el razonamiento puro dieron paso a una estructuración cada vez más sólida de lo portentoso, hasta el punto de poder hablar de influencias mutuas entre cristianismo y paganismo. La obra, el descenso, y presencia física de los dioses en la tierra mediante pruebas tangibles como curaciones, portentos, protecciones, curaciones y bendiciones, se hace esencial; se trata de fenómenos omnipresentes sin importar las creencias religiosas individuales, que deben recibir una profunda atención si se quiere entender la filosofía a partir del siglo IV y especialmente a figuras como Máximo de Éfeso o Jámblico de Calcis.

La filosofía, en las escuelas neoplatónicas tardías, estaba dividida generalmente en un número de ciencias que constituían una jerarquía de altas y bajas formas de conocimiento. Jámblico sistematizó y organizó los nuevos currículos y los puso en aplicación; tales disposiciones seguían todavía vigentes en tiempos de Proclo (Afonasin, Dillon y Finamore, 2012; O’Meara, 2006).

Se ha hablado historiográficamente de "contraataque pagano", y a nuestro entender existió una reorganización y estrategia en ciertos sectores de los cultos tradicionales. Incluso en ciertas ocasiones se quiso crear una organización terrenal pagana semejante a la de la iglesia cristiana, durante los reinados de Maximino Daza y Juliano (Jones, 1970; Nicholson, 1994).

La obra de rescate literario y propagandístico de la figura de Apolonio de Tiana debe verse y comprenderse como una táctica deliberada para oponer al portentoso sabio en oposición directa, y como contrapartida y opción contraria a Jesús y al cristianismo (Dzielska, 1986). Filóstrato, que circulaba ampliamente desde principios del siglo III sirvió de hilo conductor a todo el proceso, con frutos visibles que pueden apreciarse también en las actividades del filósofo Porfirio (c. 232-304) y muy especialmente de Virio Nicómaco Flaviano (334-394), adalid senatorial de la última resistencia armada y plenamente consciente en Occidente contra el Imperio cristiano. Como es sabido, entre sus escritos literarios compuso unos Annales que dedicó a Teodosio (en la feliz época en la que el emperador se mostraba tolerante y amistoso con los paganos), perdidos completamente, y muy en especial una traducción del griego al latín de la Vida de Apolonio (Festy, 2007; Grünewald, 1992; Hartke, 1940, 1951; Hedrick, 2000; Honoré y Matthews, 1989; Ratti, 2007). Se puede debatir el nivel de organización, pero la oposición y el enfrentamiento abierto sin duda existieron, con virulencia variable según la provincia (González-Blanco, 1998). Por su parte, Porfirio realizó una crítica demoledora de varios pasajes de las Sagradas Escrituras, expuestos con elocuencia y orden para desprestigiar en lo posible a la nueva doctrina, transgresora a sus ojos; conservamos una controvertida selección de fragmentos gracias a citas procedentes de los escritores eclesiásticos que lo combatieron, tratando de salvaguardar la credibilidad de los Evangelios ${ }^{5}$.

Este último dato es vital para comprender el ambiente político y religioso del momento; desde nuestro punto de vista la evidencia hace imposible rechazar el hecho de que al menos localmente o de modo aislado sectores paganos trataron de organizarse para resistir y hacer retroceder al cristianismo, incluso llegado el siglo $\mathrm{V}$ y la época de Mesio Febo Severo, cuando la confrontación directa al estilo de un Sosiano Herocles, Juliano o Celso era ya completamente imposible.

Después de la muerte del emperador Juliano, el filósofo pagano fue cada vez más marginado por un poder político que se esforzaba en convertirse en exclusivamente cristiano. Cuando las posibilidades de reforma política real se habían convertido en nada, cabía sólo usar la filosofía como muro y como refugio, al estilo de Sócrates (véase $P I,, R .496$ c-d.) o como Olimpiodoro, que vio su ciudad, Alejandría, dominada por violentas turbas de fanáticos y monjes cristianos que no se refrenaban a la hora de dispensar la muerte (Fowler, 2014; O'Meara, 2006). Recordemos que dicha gran ciudad, en cambio, resultó esencial para el devenir vital y académico de Mesio Febo Severo.

Desde el punto de vista académico e intelectual, las escuelas de pensamiento pagano, especialmente en Atenas y Alejandría, se centraron en la redacción y formulación explicativa en forma de comentarios de los antiguos autores, para reordenar y desgranar las explicaciones de

5 Véase la excelente traducción al español de Porfirio de Tiro, Contra los cristianos. Recopilación de fragmentos, traducción, introducción y notas de E. A. Ramos Jurado (2006). 
los textos más básicos e importantes, como los de Platón y Aristóteles, a la luz de sus propios tiempos. En este sentido, nos vemos obligados a secundar la afirmación que otorgaba a Plotino (205-270) el carácter de ser el último pensador con fuerza de todo el mundo griego (Gerson, 1996; Rist, 1967; Wagner, 2008). Los muchos y diferentes niveles del universo metafísico tal y como se comprendían en Platón fueron asociados a los dioses de la religión tradicional en el neoplatonismo tardío; Jámblico tuvo mucha importancia en esto. Por ello, dado el gran y creciente número de estadios en la purificación por medio de la filosofía, el concepto de lo divino y de la divinización también se amplió (O’Meara, 2006). Las escalas de las virtudes filosóficas incluían en su base a las virtudes políticas (O'Meara, 2006). En definitiva, la cada vez más implacable e intensa persecución ideológica y religiosa llevada a cabo por la mayoría de los emperadores cristianos lograron echar por tierra cualquier plan a largo plazo proveniente de las escuelas de filosofía, que pese a su menguante protagonismo social acabaron siendo clausuradas casi en su totalidad. La legislación imperial se ocupó también concienzudamente mediante sus decretos que el elenco de textos "ofensivos" en cuestión fuesen destruidos (Lact, Ins. V 2-5); de hecho, de la gran cantidad de autores que escribieron invectivas contra los cristianos en los siglos III y IV no nos ha quedado prácticamente nada. En Cod. lust. I 1, 3; Cod. Theod. XVI 5, 66 una ley del año 448 (emperadores Valentiniano III y Teodosio II) ordena la quema de todos los libros religiosos no cristianos, y señalando especialmente a Porfirio. Paradójicamente, en 455 el emperador Marciano ordenó la quema de los libros de Apolinar de Laodicea (c. 310 - c. 390), el obispo que había escrito la obra más concienzuda y voluminosa con fin de refutar al filósofo Porfirio; pese a tales esfuerzos acabó considerado él mismo como un hereje (Cod. lust. I 5, 8, 12). También se ordenaba en la susodicha ley la quema de los libros de Eutiques (378-456), monje griego creador del monofisismo (Ramos Jurado, 2006, 28).

Alienados y acorralados en un mundo indiferente cuando no abiertamente hostil, los últimos filósofos al viejo uso, tras la peripecia en Persia, se fueron asentando en diversas ciudades del desierto y zonas fronterizas de Oriente. Como última conjetura podríamos situar el fin de los "últimos filósofos" fieles a la antigua religión en el siglo VII (Liebeschuetz 1979; Trombley, 1993, 20).

\section{El emperador Antemio}

Antemio es considerado el último emperador capaz de Occidente capaz e independiente (O’Flynn 1983, 88-129). Durante sus siete años como Augusto llevó a cabo una política basada en honrar a las aristocracias locales, involucrar a la clase senatorial en el gobierno y asesorarse con un buen número de colaboradores de altísimo nivel cultural, casi todos ellos antiguos compañeros académicos de religión pagana: Rufino, alto oficial ateniense; Severiano, gobernador provincial de gran aplomo y sobriedad que dejó la política, harto de las asechanzas cortesanas, para convertirse en profesor; Pamprepio de Panópolis, el último gran poeta pagano; el general y patricio Marcelino, gobernante casi autócrata de Dalmacia; Flavio Ilustrio Puseo, Prefecto del Pretorio de Oriente (465) y cónsul (467), y el propio Mesio Febo Severo. Estudiaron juntos durante una o varias etapas de sus vidas. Todos ellos visitaron Atenas y Alejandría, donde fueron alumnos del célebre filósofo Proclo (O’Meara, 2003). Si a la esmerada educación recibida, de carácter liberal, sus amistades y colaboradores, añadimos ciertos rasgos y medidas religiosas de su gobierno, cabe sopesar si las acusaciones vertidas en las fuentes literarias tienen realmente algún peso (MacGeorge, 2002). No obstante, si fue el tercer miembro de su familia en apostatar después de Juliano y del conde de Oriente Juliano, homónimo y tío materno del anterior, sigue siendo un misterio. Pero en los años 469-470 eligió a un personaje singular, su amigo Mesio Febo Severo, para varias de las más altas y distinguidas dignidades del Imperio. Como veremos, tales nombramientos no dejaron de ser chocantes e inusitados.

Antemio Augusto, a diferencia de otros emperadores de Occidente en el siglo $\mathrm{V}$, recibió desde el principio el beneplácito y el reconocimiento de sus colegas orientales gracias a su procedencia noble y la proximidad a León I (Martindale, Morris y Jones, 1987); tales fenómenos pueden observarse fácilmente en la numismática del momento, así como en la legislación, la política matrimonial y el 
otorgamiento de los consulados entre 467 y 472 . Cabe destacar que antes de obtener la púrpura, nuestro personaje recibió el honor del consulado oriental en el año 455. Su colega no fue otro que el Augusto de Occidente Valentiniano III, que poco después sería asesinado (Bagnall, Cameron, Schwartz y Worp, 1987). Ese mismo año Antemio había sido elevado al rango de patricio antes del consulado, además de obtener la mano de Marcia Eufemia, única hija del emperador Marciano, con la que contrajo matrimonio. Nombrado comes rei militaris per Thracias y dotado de amplios poderes, realizó varias acciones de guerra victoriosas contra ostrogodos y hunos en el Danubio. Con el rango de magister utriusque militiae continuó realizando campañas en la parte europea del Imperio oriental, además de reforzar, reparar y rehabilitar las defensas fronterizas, muy dañadas desde los tiempos de Atila.

Perteneciente a la aristocracia oriental y la alta burocracia de Constantinopla, tanto por parte de padre como de madre, descendía directamente del Procopio usurpador de los años 365-366, lo que le hacía llevar sangre de la familia materna de Juliano, pudiendo así proclamar su parentesco remoto con los Segundos Flavios (Amm. Marc. XXVI, 6-10; Martindale et al., 1987; Matthews, 1989).

Una vez asentado en Italia, recibió la obediencia y sumisión inmediata tanto del Senado como de las partes aún dependientes y fieles al Imperio, que para su desgracia habían menguado por la presencia de los primeros reinos bárbaros ya establecidos en suelo romano (O'Flynn, 1983). Para recalcar su importancia y la deferencia con la que se le observaba, destacaremos que para el año siguiente Antemio recibió el distinguido honor del consulado en solitario, siendo cónsul único para ambas mitades del Imperio (Bagnall et al. 1987).

Se conocen los nombres de cinco vástagos del matrimonio con Eufemia: Alipia, la única hija, que casaría con Ricimero, y los varones Flavio Marciano, Rómulo, Antemiolo y Procopio Antemio, que le acompañaron a Occidente, pues uno desempeñó el consulado, y Antemiolo, al parecer el primogénito, murió en combate contra los visigodos en 471 (Martindale et al., 1987; O’Flynn, 1983; Sidon., Epist. I 5 10-11).

\section{La figura de Mesio Febo Severo en las fuentes y su relación con la cultura}

(Flavio) Mesio Febo Severo (Martindale et al., 1987; Seeck, RE II A 2 1923, s. v. Severus 43; Sundwall, 1915) resulta el ejemplo paradigmático de noble romano valedor de la cultura y las tradiciones ancestrales de los de su clase (Chastagnol, 1966). Oriundo de Roma (Dam., Vita Isidorii, en el Epít. de Phot., IX, 64, 6), Severo se hizo pronto famoso por reunir una excelente y amplísima biblioteca. Marchó a completar sus estudios a Alejandría, probablemente antes de 467, donde la escuela de filosofía todavía funcionaba a pleno rendimiento. Una pintoresca historia, que muy bien podría ser cierta, relata que verdaderos Brahmanes visitaron a Severo en Alejandría, atraídos por las noticias que le hacían poseedor de una amplísima y excelente biblioteca (Phot., Bibl. 181). Pese a la destrucción del templo de Serapis en 391 y de su inferioridad numérica, la enseñanza tradicional permanecía fiel a los cultos tradicionales, y la religión pagana dentro del profesorado y los alumnos de filosofía aún resultaba notable, e incluso mayoritaria (Watts, 2008). Se puede considerar que, aunque no poseyese los antiguos lugares de culto, el paganismo en Alejandría estaba operativo. Posiblemente, en el ámbito académico y en las artes liberales los paganos seguían siendo dominantes, cuando no imprescindibles, en centros como Atenas o la ya mencionada Alejandría. Prueba de ello puede resultar la vitalidad que mantuvo la escuela filosófica de la ciudad hasta bien entrado el siglo VI.

Durante sus estudios, Severo pudo conocer e intimar con varias personalidades que después serían claves en la política imperial, tanto oriental como occidental y que, al igual que él, casi siempre seguían manteniendo abiertamente la devoción por los cultos tradicionales. Uno de esos compañeros de estudios fue el futuro emperador Antemio, con el que, al parecer, trabó una especial amistad ya entonces. Se habla también del posterior general y patricio Marcelino, y del poeta Pamprepio de Panópolis, considerado un "segundo Claudiano" y el último gran poeta pagano del Mundo Antiguo (O’Flynn, 1983; Kaster, 1997). 
Al parecer este grupo de amigos también acudió durante un tiempo considerable a las lecciones del filósofo Proclo de Atenas (412-485), considerado como uno de los últimos grandes estandartes de la Filosofía antes de la llegada de la Edad Media (Chlup, 2012; Gersh, 2014; Siorvanes, 1996; Vassili, 1938).

Cuando Antemio alcanzó el poder en Roma, llamó a sus antiguos compañeros de estudio a su lado; vemos aquí como se repite parcialmente la historia del emperador Juliano. Severo aceptó servir en la corte, aunque al parecer en torno a 469 sufrió un desencanto con la "política real" que le hizo retirarse por un tiempo de las tareas de gobierno (Dam., fr. 117, ed. Zintzen, p. 97). Pese a tales decepciones, nunca perdió su simpatía e ilusión por Antemio, ya que regresó, seguramente a petición del mismo emperador, y ocupó el distinguido cargo de Prefecto de la Ciudad de Roma. Se han conservado varias inscripciones a su nombre en la ciudad, CIL VI 32188, 32189 y 32091 , y sabemos que suyos fueron varios proyectos de reparación y restauración de edificios públicos (Chastagnol, 1966; Henning, 1995). En las dos primeras aparece como vir illustris, es decir, como integrante de la clase senatorial más alta. Además, estos epígrafes demuestran que Severo fue consul ordinarius y praefectus urbis Romae durante el reinado de Antemio. Parece, además, que ejerció la prefectura después de su consulado (Henning, 1995), aunque tanto Chastagnol como en la PLRE consideran que fue anterior (Chastagnol, 1966; Martindale, Morris y Jones, 1987). Del mismo modo se manifiesta Vassili (1938). Se ha querido ver en tales obras un intento de puesta en valor del símbolo por antonomasia de la Roma pagana. Pese a que las funciones gladiatorias y las luchas de fieras llevaban prohibidas mucho tiempo, posiblemente el edificio, casi abandonado entonces, aún resultaba ominoso para un número importante de cristianos.

Siendo prefecto, el emperador le reservó también el honor del consulado para el año 470. Así, se dio una situación tremendamente anómala en la Roma del Bajo Imperio, pues esa magistratura estaba siendo ostentada por un personaje que proclamaba su credo pagano abiertamente, en una fecha excepcionalmente tardía (Bagnall et al., 1987). Su colega Jordanes (un general del ejército) fue elegido por el Imperio de Oriente, y ambos fueron reconocidos en todos los dominios romanos, con lo que se prueba nuevamente la excelente relación de los dos emperadores de entonces.

Que el propio Antemio fuese un adorador de los dioses en secreto, dadas todas estas circunstancias, no es descartable. De hecho, el también pagano Damascio, otro estudiante y después maestro de filosofía, le atribuye un plan para la reapertura de los templos (Athanassiadi 1999; MagGeorge, 2002). Recuérdese que una ley del año 452, promulgada por los emperadores Marciano y Valentiniano III, había prohibido la reapertura de los templos (Cod. Iust. I 11, 7).

Hasta qué punto era factible un proyecto de restauración de la religión romana a esas alturas, resulta difícil de discernir; pero bien es cierto que la mayoría del ejército seguía adicto a una religión mixta de claro sesgo pagano en Occidente. Sin centrarnos en ciertas ciudades donde cultos locales aún eran especialmente sentidos, pese a la cristianización y las conversiones, los datos arqueológicos que van surgiendo nos mueven a pensar en un sincretismo entre las viejas tradiciones y prácticas con nuevas aportaciones mistéricas, cristianas, maniqueas e incluso judías (Brody y Hoffman, 2011; Gwynn y Bangert, 2010). No había demasiado rigorismo en ese ámbito, ni aparentes preocupaciones teológicas. Una gran cantidad de los pueblos germánicos (con presencia significativa de guerreros) poblaban las antiguas provincias romanas. Éstos se podrían considerar aún religiosamente ambiguos, de tal forma que podrían tomar parte en una hipotética restauración pagana. De haber triunfado Antemio en sus campañas militares contra los visigodos y vándalos, probablemente una política de tolerancia religiosa hubiese sido recibida de una forma mucho más favorable (McCormick, 1990). La progresiva recuperación de los cultos hubiese llegado después, si bien muy lentamente. Pero respecto a la sociedad tardía, parece evidente considerar que un emperador victorioso era mucho más escuchado.

Sobre el fin de Febo Severo, nada se sabe con certeza, salvo que no pereció junto al emperador o sus otros amigos. Que se le permitiese continuar una vida tranquila dedicada a los estudios en Roma resulta lo más plausible, pues no hay documentadas represalias sobre su persona. No contamos con más evidencias. Desconocemos su fecha de nacimiento, pero permaneció vivo 
todavía durante bastante tiempo, aunque falleció antes del año 490 ( Anders, 2010; Cooper y Hillner, 2007; Henning, 1999; Wiemer, 2006).

\section{Reflexiones Finales}

Pese a tratarse de una fecha excepcionalmente tardía, vemos que la figura del emperador de Occidente, si bien con el respaldo expreso de Constantinopla, fue aún suficientemente poderosa para imponer nombramientos que pudieron resultar controvertidos, especialmente a ojos de la Iglesia y de las aristocracias romanas cristianizadas. Pero lo significativo es que uno de los mayores exponentes del paganismo romano en el siglo $\mathrm{V}$ resultó premiado con dignidades de máximo nivel, cónsul y Prefecto de la Ciudad de Roma.

Si bien desde la historiografía se acusó a ambos (Severo y Antemio) de tramar la reapertura de los templos y la restauración de los cultos tradicionales, no se encuentra documentada ningún tipo de oposición institucional o estamental serias, aunque bien es cierto que, de ser real el hipotético paganismo del emperador, éste no lo mostró jamás en público. De hecho, en una de las visitas a la basílica de san Pedro, el papa Hilario (461-468), obligó al emperador a jurar sobre la tumba del Apóstol que jamás permitiría concilios y asambleas heréticas en Roma. Uno de los amigos de Antemio, Filoteo, era semiarriano, un seguidor de la denominada herejía macedonia; de ahí el temor del obispo (Vassili, 1938, 41). Según el Chron. Alex. 469, Antemio habría dedicado una iglesia en Constantinopla al apóstol Tomás. En cualquier caso, su hipotética conversión pudo llegar más tarde, como en el caso de su antepasado Juliano, de credo cristiano arriano al principio.

Podemos comprobar como las redes clientelares a finales del siglo $\mathrm{V}$ no vieron como movimientos transgresores la preponderancia en el gobierno de paganos militantes; pesó quizás mucho más en su contra el carácter y la cultura de Antemio, un griego noble de Constantinopla, antes que sus medidas de connotaciones religiosas. Encontramos, así, las particularidades y fobias del localismo romano todavía operativas.

El fin de Antemio, y por ende el fin de la importancia política de sus colaboradores, no vino por asuntos relativos a la religión; pesaron de modo decisivo las derrotas sufridas por el emperador, que condujeron a una situación límite. Fueron también factores importantes tanto la mala suerte como la traición. Con la llegada de Olibrio al poder, en cambio, la figura imperial dejó de tener peso y desapareció definitivamente como uno de los factores a tener en cuenta en las ecuaciones relativas a la guerra y la política en el Imperio Romano de Occidente.

\section{Abreviaturas}

CIL VI. Königlich Preussische Akademie der Wissenschaften zu Berlin, Corpus Inscriptionum Latinarum (Berlin 1893-).

RE. Pauly, A. y Wissowa, G. Real-Encyclopädie der Classischen Altertumswissenschaft (18931978).

PLRE. Martindale, J. R., Morris, J., y Jones, A. H. M. (1987). The Prosopography of the Later Roman Empire vol. II, 395-527 A. D. Cambridge University Press.

\section{Bibliografía}

Afonasin, E., Dillon, J. M. y Finamore, J. (eds.) (2012). lamblichus and the Foundations of Late Platonism. Leiden: Brill.

Alföldi, A. (1979). A Conflict of ideas in the Later Roman Empire. Oxford: Oxford University Press. Anders, F. (2010). Flavius Ricimer: Macht und Ohnmacht des weströmischen Heermeisters in der zweiten Hälfte des 5. Jahrhunderts (= Europäische Hochschulschriften. Reihe 3: Geschichte und ihre Hilfswissenschaften. Bd. 1077). Frankfurt am Main: Lang. 
Bagnall, R. S, Cameron, A. C., Schwartz, S. R. y Worp, K. A. (1987). Consuls of the Later Roman Empire. Atlanta: American Philological Association.

Blumenthal, H. J. (1978). 529 and its sequel: What happened to the Academy? Byzantion, 48 (2), 369-385.

Bravo, G. (2010). Teodosio: último emperador de Roma, primer emperador católico. Madrid: La Esfera de los Libros.

Brody, L. R. y Hoffman, G. L. (2011). Dura-Europos: Crossroads of Antiquity. Boston: Gail L. Hoffman. Brown, P. (1971). The Rise and Function of the Holy Man in Late Antiquity. Journal of Roman Studies, $66,73-114$.

Brown, P. (1989). El Mundo en la Antigüedad Tardía. De Marco Aurelio a Mahoma. Madrid: Taurus.

Brown, P. (1997). Authority and the Sacred: Aspects of the Christianization of the Roman World. Cabridge: Cambridge University Press.

Busine, A. (ed.) (2015). Religious Practices and Christianization of the Late Antique City (4th - 7th centuries). Leiden: Brill.

Cameron, A. (2010). The Last Pagans of Rome. Oxford: Oxford University Press.

Chastagnol, A. (1966). Le sénat romain sous le règne d'Odoacre. Recherches sur l'Épigraphie du Colisée au Ve siècle. Bonn: R. Habelt.

Chlup, R. (2012). Proclus: An Introduction. Cambridge: Cambridge University Press.

Dzielska, M. (1986). Apollonius of Tyana in Legend and History. Roma: ,L'Erma' di Bretschneider.

Ernesti, J. (1998). Princeps Christianus und Kaiser aller Römer: Theodosius der Grosse im Lichte zeitgenössischer Quellen. Paderborn: F. Schöningh.

Fernández, G. (1983). Justiniano y la clausura de la escuela de Atenas. Erytheia, 2, 24-30.

Festy, M. (2007). L'Histoire Auguste et les Nicomaques. En Bonamente, G., y Brandt, H. (eds.), Historiae Augustae Colloquium Bambergense (pp. 183-195). Bari: Edipuglia srl.

Fowden, G. (1982). The Pagan Holy Man in Late Antique Society. Journal of Roman Studies, 102, 33-59.

Francis, J. A. (1995). Subversive Virtue: Asceticism and Authority in the Second-Century Pagan World. Pennsylvania: Penn State Press.

Gersh, S. (ed.) (2014). Interpreting Proclus. Cambridge: Cambridge University Press.

Gerson, L. P. (ed.) (1996). The Cambridge Companion to Plotinus. Cambridge: Cambridge University Press.

Gigon, O. (1970). La cultura antigua y el cristianismo. Madrid: Gredos.

González-Blanco, A. (1998). Historia de Murcia en las épocas: Tardorromana, Bizantina y Visigoda. Murcia: Universidad de Murcia (Editum).

Griffin, M. (2014). "Pliable Platonism"? Olympiodorus and the Profession of Philosophy in Sixth Century Alexandria. En Fowler, R. C. (ed.), Plato in the Third Sophistic (pp. 73-100). Berlin: W. de Gruyter.

Grünewald, T. (1992). Der letzte Kampf des Heidentums in Rom? Zur posthumen Rehabilitation des Virius Nicomachus Flavianus. Historia, 41, 462-487

Gwynn, D. M., Bangert, S. (eds.), 2010. Religious Diversity in Late Antiquity. Leiden: Brill.

Hartke, W. (1940). Geschichte und Politik im spatantiken Rom. Leipzig: Dieterich.

Hartke, W. (1951). Römische Kinderkaiser: eine Strukturanalyse römischen Denkens und Daseins. Berlin: Akademie-Verlag.

Heather, P. (2006). La Caída del Imperio Romano. Barcelona: Planeta.

Hedrick, C. W., Jr. (2000). History and Silence: The Purge and Rehabilitation of Memory in Late Antiquity. Austin: University of Texas Press.

Henning, D. (1999). Periclitans Res Publica. Kaisertum und Eliten in der Krise des Weströmischen Reiches 454/5-493 n. Chr. Stuttgart: Franz Steiner Verlag.

Honoré, T., y Matthews, J. (1989). Virius Nicomachus Flavianus. Konstanz: Universitatsverlag.

Humphries, M. (2007). From Emperor to Pope? Ceremonial, Space and authority at Rome from Constantine to Gregory the Great. En Cooper, K., Hillner, J., (eds.), Religion, Dynasty, and 
Patronage in Early Christian Rome, 300-900 (p. 43). Cambridge: Cambridge University Press. Jones, A. H. M. (1970). The Social Background of the Struggle between Paganism and Christianity.

En Momigliano, A. (ed.), The Conflict between Paganism and Christianity in the Fourth Century (pp. 17-37). Oxford: Oxford University Press.

Kaster, R. A. (1997). Guardians of Language: The Grammarian and Society in Late Antiquity. Berkeley: University of California Press.

Lee, A. D. (2000). Pagans and Christians in Late Antiquity: A Sourcebook. London: Routledge.

Lee, A. D. (2013). From Rome to Byzantium AD 363 to 565: The Transformation of Ancient Rome. Edinburgh: Edinburgh University Press.

Leppin, H. (2009). Teodosio. Barcelona: Herder.

Liebeschuetz, J. H. W. G. (1979). Continuity and Change in Roman Religion. Oxford: Oxford University Press.

Lieu, S. y Montserrat, D. (eds.), 1996. From Constantine to Julian. Pagan and Byzantine Views: A Source History. London: Psychology Press.

MacGeorge, P. (2002). Late Roman Warlords. Oxford: Oxford University Press.

MacMullen, R. (1981). Paganism in the Roman Empire. New Haven-London: Yale University Press.

MacMullen, R. (1984). Christianizing the Roman Empire (A. D. 100-400). New Haven-London: Yale University Press.

MacMullen, R. (1997). Christianity and Paganism in the Fourth to Eighth Centuries. New HavenLondon: Yale University Press.

Martindale, J. R., Morris, J. y Jones, A. H. M. (1987). The Prosopography of the Later Roman Empire vol. II, 395-527 A. D. Cambridge: Cambridge University Press.

Matthews, J. F. (1989). The Roman Empire of Ammianus. Baltimore: Michigan Classical Press.

McCormick, M. (1990). Eternal Victory: Triumphal Rulership in Late Antiquity, Byzantium and the Early Medieval West. Cambridge: Cambridge University Press.

McKenna, S. (1938). Paganism and Pagan Survivals in Spain: Up to the Fall of the Visigothic Kingdom. Washington: Catholic University of America.

Montero, S. (1990). El papa Inocencio I ante las tradiciones religiosas paganas. Antigüedad y Cristianismo, VII, 405-412.

Nicholson, O. (1994). The Pagan Churches of Maximinus Daia and Julian the Apostate. The Journal of Ecclesiastical History, 45, 1-10.

O’Flynn, J. M. (1983). Generalissimos of the Western Roman Empire. Edmonton: Alberta University Press.

O’Meara, D. J. (2003). Platonopolis. Platonic Political Philosophy in Late Antiquity. Oxford: Clarendon Press.

O'Meara, D. J. (1990, 2006). Pythagoras revived: Mathematics and Philosophy in Late Antiquity. Oxford: Clarendon Press.

Ramos, E. A. (2006). De Platón a los neoplatónicos: la escritura y el pensamiento griegos. Madrid: Síntesis.

Rapp, C. (2013). Holy Bishops in Late Antiquity: The Nature of Christian Leadership in an Age of Transition. Berkeley: University of California Press.

Ratti, S. (2007). Nicomaque Flavien senior auteur de l'Histoire Auguste., en Bonamente, G., y Brandt, H. (eds.), Historiae Augustae Colloquium Bambergense (pp. 305-317). Bari: Edipuglia srl.

Rist, J. M. (1967). Plotinus: Road to Reality. Cambridge: Cambridge University Press.

Salzman, M. R. (2002). The Making of a Christian Aristocracy: Social and Religious Change in the Western Roman Empire. Cambridge (Mass.): Harvard University Press.

Salzman, M. R., Sághy, M. y Testa, R. L. (2015). Pagans and Christians in Late Antique Rome: Conflict, Competition, and Coexistence in the Fourth Century. Cambridge: Cambridge University Press.

Sánchez, E (ed.) (1986). Polémica entre cristianos y paganos a través de los textos: problemas existenciales y problemas vivenciales. Madrid: Akal.

Shanzer, D. (2016). Romans, Barbarians, and the Transformation of the Roman World: Cultural 
Interaction and the Creation of Identity in Late Antiquity. London: Routledge.

Siorvanes, L. (1996). Proclus: Neo-platonic Philosophy and Science. Edinburgh: Edinburgh University Press.

Sundwall, J. (1915). Weströmischen Studien. Berlin.

Testa, R. L., y Santini, C., (eds.) (2014). The Strange Death of Pagan Rome: Reflections on a Historiographical Controversy. Turnhout: Brepols.

Trombley, F. R. (1993). Hellenic Religion and Christianization: c.370-529 (2 vols.). Leiden: Brill. Vassili, L. (1938). La cultura di Antemio. Athenaeum, 16, 38-45.

Wagner, M. F. (2008). The Enigmatic Reality of Time: Aristotle, Plotinus, and Today. Leiden: Brill.

Watts, E. J. (2004). Justinian, Malalas and the Closing of the Athenian Neoplatonic School in A. D. 529. Journal of Roman Studies, 94, 168-182.

Watts, E. J. (2008). City and School in Late Antique Athens and Alexandria. Berkeley: University of California Press.

Watts, E. J. (2015). The Final Pagan Generation. Berkeley: University of California Press.

Wiemer, H. U. (ed.) (2006). Staatlichkeit und politisches Handeln in der römischen Kaiserzeit. Berlin: W. de Gruyter.

Williams, S. y Friell, G. (1994). Theodosius: The Empire at Bay. London: Routledge.

\section{Fuentes}

Amiano Marcelino, Historia (Res Gestae). Madrid: Akal Clásica. 2002. [Edición y traducción de María Luisa Harto Trujillo].

(Chronicum Alexandrinum) Chronicon Paschale 284-628 AD. Liverpool: Liverpool University Press. 1989. [Traducción de Michael Whitby and Mary Whitby].

Codex Iustinianus. XXVIII, [4] (Corpus luris civilis; 2). Dublin: Apud Weidmannos. 1967. [recognovit et retractavit Paulus Krueger. $14^{a}$ ed.].

Codex Theodosianus (3 vols.). Hildesheim: Wiedmann, 1990. [Edición de Th. Mommseno, Paulus M. Meyer].

Damascius. The Philosophical History. Athens: Apamea Cultural Association. 1999. [Edición de P. Athanassiadi].

Viața lui Isidor = Damascii vitae Isidori reliquiae. Hildesheim: Olms. 1976. [Edición de C. Zintzen]

Juliano. Contra los Galileos; Cartas y fragmentos; Testimonios; Leyes. Madrid: Gredos. 1982. [Introducción, traducción y notas por José García Blanco y Pilar Jiménez Gazapo].

Lactancio, Lucio Celio Firmiano. Instituciones Divinas. Madrid: Gredos. 1990. [Introducción, traducción y notas de Eustaquio Sánchez Salor].

Platón. La República. Madrid: Alianza Editorial. 2006. [Introducción de Manuel Fernández-Galiano; traducción de J. M. Pabón y Manuel Fernández-Galiano].

Photius lexicographus. Bibliotheca. Berlín: W. de Gruyter. 1982-1998. [Edición de Ch. Theodoridis]

Porfirio de Tiro. Contra los cristianos. Cádiz: Universidad de Cádiz. 2006. [Recopilación de fragmentos, traducción, introducción y notas de Enrique Ángel Ramos Jurado]. 


\section{Panta Rei}

PANTA REI es una revista digital de investigación orientada a la Historia y otras ciencias afines. Su principal objetivo es la transmisión del conocimiento científico, dando una oportunidad también a los jóvenes investigadores que quieren abrirse camino en el estudio de las ciencias humanas y sociales. Se compone de estudios originales relacionados con la disciplina histórica así como su didáctica y difusión. Las diferentes secciones que componen la revista son: artículos de investigación, entrevistas a profesionales, recensiones de monografías de actualidad y crónicas de congresos o eventos científicos relevantes.

Todos los artículos publicados son objeto de un proceso de revisión a cargo de un mínimo de dos evaluadores, que se consideran expertos en el ámbito temático del artículo propuesto. Nuestro deseo es poder ofrecer unos contenidos rigurosos, de calidad y de interés.

EI CEPOAT (Centro de Estudios del Próximo Oriente y la Antigüedad Tardía de la Universidad de Murcia) es la institución encargada de la coordinación y gestión de la revista, desde donde anualmente se lanzará la convocatoria para aquellos que estén interesados en publicar sus trabajos, siempre relacionados con la Historia, Arqueología, Historia del Arte, Didáctica de las Ciencias Sociales, etc.

PANTA REI is a digital journal focused on History and other sciences related to it. Its main objective is the transmission of scientific knowledge by giving also an opportunity to young researchers who want to make their way in the study of human and social sciences. It is composed by original studies related to History, as well as its didactics and promotion. The different sections of this journal are: research articles, interviews to professionals, recensions on monographs about current issues and reports about congresses or relevant scientific events.

All the articles published are subject to a revision process carried out by a minimum of two reviewers who are considered to be experts in the field of the article proposed. Our wish is to offer rigorous contents with quality and being of interest to the reader.

CEPOAT (Centre of Studies of the Middle East and Late Antiquity of the University of Murcia) is the institution in charge of the coordination and management of this journal. This is the centre from where the call for papers will be launched for all the people interested in publishing their papers, always related to History, Archeology, Art History, Didactics of the Social Sciences, etc. 


\section{Normas de Publicación}

El autor se compromete a enviar trabajos originales, que no se encuentren publicados en otras revistas ni en otros idiomas. Así mismo, el mismo artículo no podrá ser presentado en otras revistas mientras dure el proceso de evaluación.

\section{Envío y presentación de originales}

Los artículos se enviarán exclusivamente a través del correo electrónico a la dirección pantarei@um.es. Los textos serán enviados en formato DOC y las imágenes en formato JPEG o TIFF, y con un tamaño mínimo de 2000 px. Éstas no aparecerán incorporadas en el texto, sino enviadas en archivo aparte y correctamente numeradas según su posición en el texto. Junto al trabajo, se rellenará y enviará un documento aparte en el que se especifiquen los datos del autor siguiendo el modelo disponible en la página Web de la revista.

Para la redacción de los trabajos se tendrá en cuenta el Manual de la American Psychological Association, en su sexta edición. La extensión máxima de los trabajos será de 30 páginas. La tipografía será Arial 11, con interlineado sencillo y sin espacio alguno entre párrafos. El texto deberá ir justificado a ambos márgenes y sin sangría en los primeros párrafos. Los márgenes serán de $2,50 \mathrm{~cm}$. En los casos en los que fuera necesario incorporar notas, éstas irán a pie de página, enumeradas consecutivamente, con tipografía Arial 10, interlineado sencillo y justificadas a ambos márgenes.

Una información más detallada se encuentra disponible en la página http://www.um.es/cepoat/ pantarei.

\section{Proceso de valoración y evaluación}

Una vez recibidos los trabajos, la Revista realizará una primera valoración. Si el trabajo enviado se ajusta a las normas de presentación propuestas, la temática es coincidente con la línea editorial de la revista y posee la calidad científica necesaria, será remitido al consejo asesor para una primera evaluación. Si no es así en este primer paso se puede rechazar directamente los documentos que incumplan claramente la línea editorial.

Será el Consejo Asesor quien indique a la revista la originalidad, relevancia, estructura, redacción, aparato bibliográfico, etc. del trabajo enviado y, para ello, se designará a dos revisores expertos externos que evaluarán cada uno de los trabajos, que pueden formar parte (o no) de este Consejo Asesor. La selección de los revisores se ajustará a la temática y características metodológicas del trabajo. El nombre y filiación de los autores serán eliminados del trabajo para su revisión, así como los revisores actuarán de manera anónima y confidencial.

Los revisores deberán rellenar un informe de evaluación que centrará su atención en aspectos tales como características formales, originalidad y novedad de los trabajos, relevancia de las propuestas y los resultados, calidad metodológica y validez científica.

Una vez terminado el proceso se decidirá la aceptación o no de los mismos y su publicación en el número que sea pertinente, así como las modificaciones susceptibles de ser realizadas para su final publicación. Dicha notificación se enviará únicamente por correo electrónico, en un plazo máximo de seis meses. 


\section{Publishing rules}

The author is committed to submit original papers not having been published in other reviews or in other languages. In this way, it is not allowed for the same paper to be presented in other reviews during the evaluation process.

\section{Submission and presentation of originals}

The articles will be exclusively submitted by email to pantarei@um.es. The texts will be submitted in DOC format and the images in JPEG or TIFF format, and with a minimum size of 2000 px. Images will not be integrated in the text but sent in another file and properly numbered according to their position in the text. Attached to the paper, a document will be filled out and sent where the author's data will be specified following the model available on the website.

The sixth edition of the Manual of the American Psychological Association will be taken into account for the writing of the papers. The length of the papers must not exceed 30 pages. Typography will be Arial 11 , with simple line spacing and no space between paragraphs. The text must be justified on both margins without indentation in the first paragraphs. Margins size will be $2.50 \mathrm{~cm}$. Where it could be necessary the incorporation of notes, they will be at the bottom of the page, consecutively numbered with typography Arial 10, simple line spacing and justified on both margins.

More detailed information is available on the website: http://www.um.es/cepoat/pantarei.

\section{Examination and assessment process}

The Journal will submit the papers to a first examination once received. If the paper follows the presentation guidelines, the subject agrees with the editorial line of this journal, and possess the scientific quality required, it will be sent to the advisory council for a first assessment. If not, the documents which clearly fail to complete the editorial line may be rejected straightaway in this first step.

The Advisory Council will indicate the originality, relevance, structure, writing, bibliography, etc. of the text to the journal; for this purpose, two outside experts will be designated to review the papers; these experts can be (or not) part of this Advisory Council. The selection of the experts will adjust to the subject and methodological characteristics of the paper. Name and affiliation of the author will be eliminated from the text for its review, in this way experts will act anonymously and confidentially.

The experts will fill out an assessment report which will focus on aspects such as formal characteristics, originality and novelty of the papers, relevance and results of the proposal, methodological quality and scientific validity.

Once the process is finished, the acceptance or not of the papers and its publication in the corresponding edition will be decided, as well as the modifications that may be done for its final publication. This notification will be sent by email within 6 months maximum. 



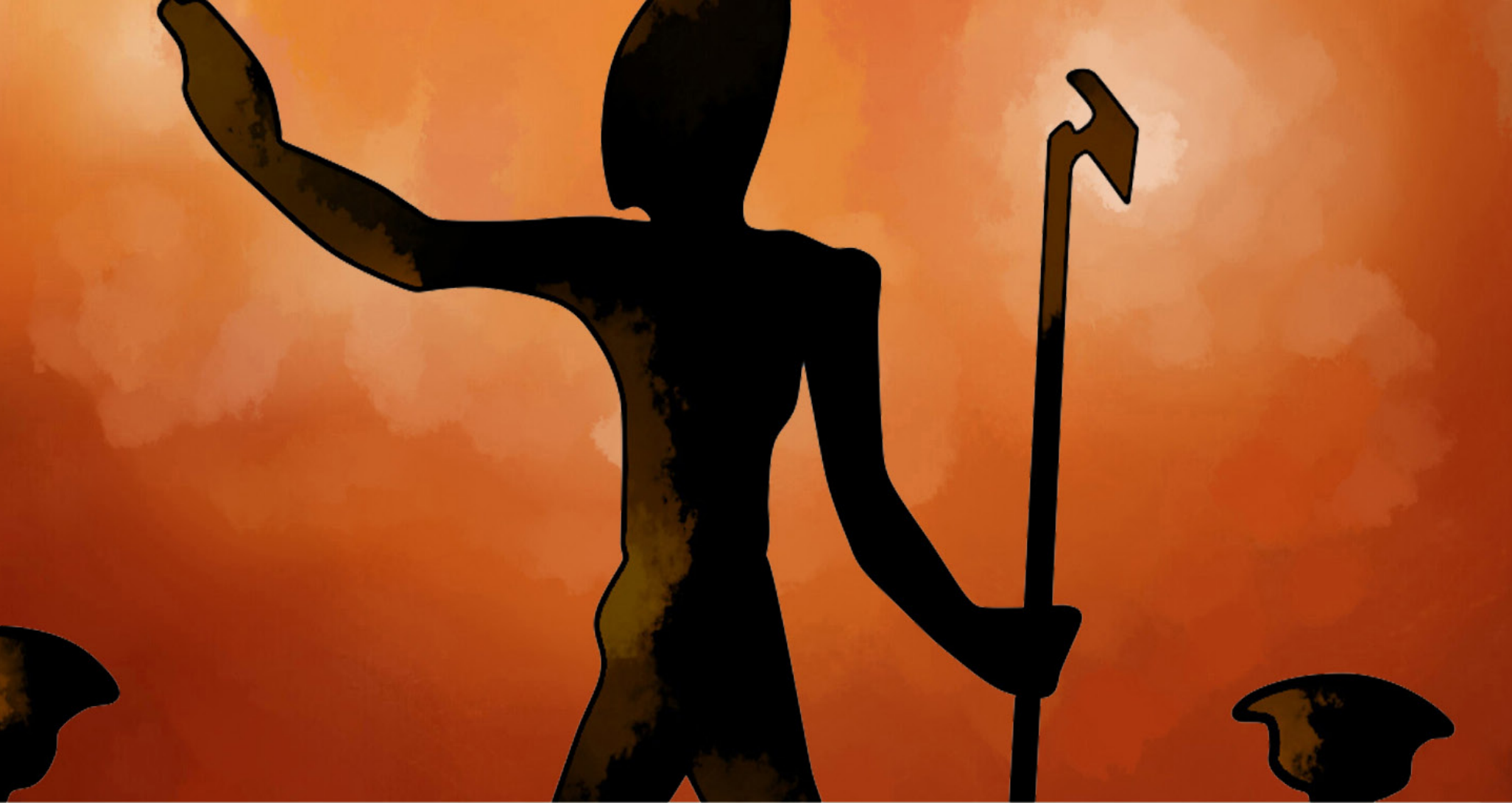

\section{cepoAt}

UNIVERSIDAD DE MURCIA

centro de estudios del

próximo oriente y la

antigüedad tardía 